\title{
Insufficient Natriuretic Response to Continuous Intravenous Furosemide Is Associated with Poor Long-Term Outcomes in Acute Decompensated Heart Failure
}

\author{
Dhssraj Singh, MD ${ }^{1}$, Kevin Shrestha, MD², Jeffrey M. Testani, MD MTR ${ }^{3}$, Frederik H. \\ Verbrugge, MD ${ }^{4,5}$, Matthias Dupont, $\mathbf{M D}^{4}$, Wilfried Mullens, MD, $\mathbf{P h D}^{4,5}$, and $\mathbf{W}$. H. Wilson \\ Tang, MD ${ }^{2}$ \\ ${ }^{1}$ Division of Cardiovascular Diseases, Department of Medicine, University of Kansas, Kansas \\ City, Kansas \\ ${ }^{2}$ Department of Cardiovascular Medicine, Heart and Vascular Institute, Cleveland Clinic, \\ Cleveland, Ohio \\ ${ }^{3}$ Department of Internal Medicine and Program of Applied Translational Research, Yale, \\ University School of Medicine, New Haven, CT \\ ${ }^{4}$ Department of Cardiology, Ziekenhuis Oost-Limburg, Genk, Belgium \\ ${ }^{5}$ Doctoral school for Medicine and Life Sciences, Hasselt University, Diepenbeek, Belgium
}

\begin{abstract}
Background-Treatment of acute decompensated heart failure with loop diuretics such as furosemide is frequently complicated by insufficient urine sodium excretion. We hypothesize that insufficient natriuretic response to diuretic therapy, characterized by lower urine sodium $\left(\mathrm{U}_{\mathrm{Na}}\right)$ and urine furosemide is associated with subsequent inadequate decongestion, worsening renal function, and adverse long-term events.
\end{abstract}

Methods and Results-We enrolled 52 consecutive patients with ADHF and measured serum and urine sodium $\left(\mathrm{U}_{\mathrm{Na}}\right)$, urine creatinine $\left(\mathrm{U}_{\mathrm{Cr}}\right)$, and urine furosemide $\left(\mathrm{U}_{\text {Furosemide }}\right)$ levels on a spot sample taken after treatment with continuous intravenous furosemide, and followed clinical and renal variables as well as adverse long-term clinical outcomes (death, rehospitalizations and cardiac transplant). We observed comparable correlations between $\mathrm{U}_{\mathrm{Na}}: \mathrm{U}_{\text {Furosemide }}$ ratio as well as $\mathrm{U}_{\mathrm{Na}}$ and fractional excretion of sodium ( $\left.\mathrm{FE}_{\mathrm{Na}}\right)$ with 24-hour net urine output $(\mathrm{r}=0.52-0.64$, all $\mathrm{p}<0.01)$ and 24-hour weight loss $(\mathrm{r}=0.44-0.56$, all $\mathrm{p}<0.01)$. Interestingly, $\mathrm{FE}_{\mathrm{Na}}$ (but not $\mathrm{U}_{\mathrm{Na}}$ or

(C) 2014 Elsevier Inc. All rights reserved.

Address for Correspondence: W. H. Wilson Tang, MD, Department of Cardiovascular Medicine, Heart and Vascular Institute, Cleveland Clinic, 9500 Euclid Avenue, Desk J3-4, Cleveland, OH 44195, Phone: 216-444-2121 / Fax: 216-445-6165 / tangw@ccf.org.

Publisher's Disclaimer: This is a PDF file of an unedited manuscript that has been accepted for publication. As a service to our customers we are providing this early version of the manuscript. The manuscript will undergo copyediting, typesetting, and review of the resulting proof before it is published in its final citable form. Please note that during the production process errors may be discovered which could affect the content, and all legal disclaimers that apply to the journal pertain.

DISCLOSURE

All the authors have no relationships to disclose related to the study. 
$\mathrm{U}_{\mathrm{Na}}: \mathrm{U}_{\text {Furosemide }}$ ) were influenced by estimated glomerular filtration rate (eGFR). We observed an association between lower $\mathrm{U}_{\mathrm{Na}}: \mathrm{U}_{\text {Furosemide }}$ with greater likelihood of worsening renal function (HR 3.01, p=0.02) and poorer adverse clinical outcomes (HR 1.63, p=0.008) after adjusting for age and eGFR. Meanwhile, both diminished weight loss and net fluid output over 24 hours of continuous intravenous furosemide were observed when $\mathrm{U}_{\mathrm{Na}}: \mathrm{U}_{\text {Furosemide }}$ ratios were $<2 \mathrm{mmol} / \mathrm{mg}$ or when $\mathrm{U}_{\mathrm{Na}}<50 \mathrm{mmol}$.

Conclusion-In patients with ADHF receiving continuous furosemide infusion, impaired natriuretic response to furosemide is associated with greater likelihood of worsening renal function and future adverse long-term outcomes that is independent and incremental to intrinsic glomerular filtration.

\section{Keywords}

Acute decompensated heart failure; furosemide; urine sodium; natriuresis

\section{INTRODUCTION}

Loop diuretics are the first-line agents for amelioration of symptoms and restoration of volume status in the treatment of acute decompensated heart failure (ADHF). ${ }^{1}$ However, a subset of patients treated for ADHF fails to elicit effective diuresis with loop diuretics despite persistent congestion. There have been several postulates to this so-called "diuretic resistance" phenomenon. ${ }^{2,3}$ First, the presence of heart failure has been shown to shift the loop diuretic dose-response curve down and to the right, with the same dose of diuretics producing an attenuated response in heart failure patients when compared to normal controls. ${ }^{4}, 5$ Second, loop diuretics have been shown to indirectly reduce renal blood flow by activation of the renin-angiotensin-aldosterone system (RAAS) and sympathetic nervous system (SNS), thereby leading to a further increase in tubular sodium absorption. The reduced renal blood flow itself may cause decreased diuretic delivery since it is predominantly secreted at the tubular level, while tubular resistance to the diuretic can be induced by the neurohormonal activation. ${ }^{6}$ Third, loop diuretic exposure has been shown to cause hypertrophy of distal tubular epithelial cells with enhanced distal sodium absorption. ${ }^{7}$ While in most cases, healthcare providers determine effective diuretic dosing via assessment of urine output and weight loss over the course of treatment with loop diuretics, few simple bedside measures are reliable in determining real-time diuretic effectiveness. ${ }^{8}$ Herein, we investigate the clinical significance of the natriuretic response to loop diuretic therapy in terms of the development of adverse clinical outcomes, and examine the clinical utility of measuring spot urine electrolytes as potential bedside tools to determine the effectiveness of decongestion strategies during continuous intravenous loop diuretic therapy.

\section{METHODS}

\section{Study Population}

We prospectively enrolled consecutive subjects 18 years or older who were admitted to the hospital with a clinical diagnosis of acute decompensated heart failure, including evidence of fluid overload ( $2+$ lower extremity edema or more, presence of pulmonary edema or 
pleural effusion on chest radiograph, jugular venous distention, worsening dyspnea, orthopnea, paroxysmal nocturnal dyspnea, or ascites, or increase in body weight from baseline that was attributed to fluid retention. We only included those receiving a continuous infusion of furosemide for at least more than 3 hours and less than 24 hours at the discretion of the treating physician due to the need to establish a steady-state systemic level of furosemide in order to reliably assess natriuretic response via the measurement of urinary furosemide by spot collection. The purpose is to identify a patient while congestion is still present and effective diuresis is still occurring yet long enough for furosemide to achieve relatively steady state at the urinary level. We excluded subjects who were unable to provide informed consent or comply with study protocol, on renal replacement therapy or anuric at the time of enrollment, or with anticipated hospital discharge within the next 24 hours.

\section{Study design}

This is a single-center, observational, prospective cohort study approved by the Cleveland Clinic Institutional Review Board. All subjects provided written informed consent. Treatment of heart failure including diuretic dosing was based on standard of care as determined by the treating physician independent of the study. Although not specified for the study, all patients were put on a low sodium ( $2 \mathrm{~g}$ ) cardiac diet as institution's standard of care for heart failure admissions. In addition to this, diabetics were also put on diabetic diet. Weight loss was calculated by subtracting values 24 hours after the urine samples were measured from the weight on the day of first urine sample measurement (baseline). Fortyeight hour and 72-hour total net fluid balance from baseline were also assessed. Glomerular filtration rate (eGFR) was estimated by the Modified Diet and Renal Disease (MDRD) equation. Patients were followed for 5 days or discharge upon enrollment, and electronic medical record follow-up of adverse long-term outcomes were tracked as secondary endpoint until study completion (August 2010).

\section{Assay measurements}

Urine sodium $\left(\mathrm{U}_{\mathrm{Na}}\right)$ concentration from spot urine samples was measured by ion selective electrode and urine creatinine $\left(\mathrm{U}_{\mathrm{Cr}}\right)$ was measured by enzymatic assay within the Cleveland Clinic Reference Laboratory. Urinary furosemide ( $\left.\mathrm{U}_{\text {Furosemide }}\right)$ from spot urine samples was assessed by NMS Labs (Willow Grove, PA) utilizing high performance liquid chromatography. We defined the natriuretic response to furosemide as the ratio of $\mathrm{U}_{\mathrm{Na}}$ and $\mathrm{U}_{\text {Furosemide, }}$ expressed as $\mathrm{mmol} / \mathrm{mg}$. Fractional excretion of sodium $\left(\mathrm{FE}_{\mathrm{Na}}\right)$ was calculated as: $\left(\mathrm{U}_{\mathrm{Na}} \times \mathrm{S}_{\mathrm{Cr}}\right) /\left(\mathrm{U}_{\mathrm{Cr}} \times \mathrm{S}_{\mathrm{Na}}\right) \times 100 \%$. Worsening renal function $(\mathrm{WRF})$ was defined as a rise in serum creatinine of $0.3 \mathrm{mg} / \mathrm{dL}$ or more between day one and day five upon enrollment into the study. Baseline B-type natriuretic peptide (BNP) levels were measured by the Abbott Architect ci8200 platform (Abbott Laboratories, Abbott Park, IL). Physicians providing care for patients were blinded from the assay results derived from this study. Ratio of $\mathrm{U}_{\mathrm{Na}}: \mathrm{U}_{\text {Furosemide }}$ was analyzed independently and results were not available to treating physicians.

\section{Statistical Analysis}

Continuous variables were summarized as mean \pm standard deviation if normally distributed, and as median and interquartile range (IQR) if non-normally distributed. 
Normality was assessed by the Shapiro-Wilk $W$ test. Categorical variables were summarized as proportions and frequencies. Spearman's rank correlation method was used as a nonparametric measure of association for correlations between urinary electrolytes and clinical characteristics and laboratory indices. The Wilcoxon rank-sum or Kruskal-Wallis tests were used to compare differences in urinary electrolytes and non-normally distributed variables across clinical categories, while Student's $t$-test or one-way analysis of variance (ANOVA) were used to compare differences in normally distributed variables across clinical categories. Proportions were compared using contingency table analysis. The logistical regression analysis determining the odds ratio of worsening renal function (defined as a rise in serum creatinine $\geq 0.3 \mathrm{mg} / \mathrm{dL}$ ) associated with $\mathrm{U}_{\mathrm{Na}}: \mathrm{U}_{\text {Furosemide }}$ was a nominal logistic regression analysis with an effect likelihood ratio test. In multivariable logistic regression, age and eGFR were added as covariates with $\mathrm{U}_{\mathrm{Na}}: \mathrm{U}_{\text {Furosemide }}$ and tests and confidence intervals on odds ratios were again likelihood ratio based in a nominal logistic regression. Odds ratios (OR) and 95\% confidence interval $(95 \% \mathrm{CI})$ were calculated through logistic regression analysis and evaluated according to the likelihood ratio test. Kaplan-Meier survival plots were calculated from baseline to time of all-cause mortality, cardiac transplantation or heart failure re-hospitalization. The Cox proportional hazards regression model was used to analyze time to all-cause mortality, cardiac transplantation or heart failure rehospitalization associated with decreasing urinary analyte levels (with natural logarithmic transformation). Increments were made per natural logarithmic standard deviation increase $\left(\mathrm{U}_{\mathrm{Na}}=0.87 \mathrm{mmol} ; \mathrm{U}_{\mathrm{Na}}: \mathrm{U}_{\text {Furosemide }}=1.54 \mathrm{mmol} / \mathrm{mg} ; \mathrm{FE}_{\mathrm{Na}}=1.47\right)$. Optimal cut-off values were determined by Receiver Operator Characteristic (ROC) curve, and area under ROC curve (AUC). The proportional hazards assumption was verified with log(time) vs. $\log [-\log ($ survival $)]$ plots. All p-values reported are from two-sided tests and a p-value $<0.05$ was considered statistically significant. Statistical analyses were performed using JMP 10.0.0 (SAS Institute, Cary, NC).

\section{RESULTS}

\section{Baseline characteristics}

A total of 52 consecutive patients that fulfilled the inclusion and exclusion criteria were enrolled between October 2009 and March 2010. Table 1 illustrates the characteristics of our study cohort at time of enrollment and the indices of urine sodium excretion, which was stratified according to above versus below the median eGFR at baseline $(50 \mathrm{~mL} / \mathrm{min} /$ $1.73 \mathrm{~m}^{2}$ ). In our study cohort, $11 \%$ of patients had LVEF $\geq 50 \%$, and $22 \%$ had LVEF $\geq 40 \%$.

The clinical characteristics were relatively well-matched with the exception of more patients having a history of diabetes mellitus in the group with eGFR $<50 \mathrm{ml} / \mathrm{min} / 1.73 \mathrm{~m}^{2}$. In addition to furosemide, $35 \%(\mathrm{n}=18)$ of patients were also concurrently treated with thiazide or potassium sparing diuretics. In all cases, patients were treated with decongestive therapy beyond 24 hours. The mean number of days patients were on furosemide infusion after enrollment in the study was $4.2 \pm 1.2$ days.

We observed that baseline $\mathrm{U}_{\mathrm{Na}}: \mathrm{U}_{\text {Furosemide }}$ ratio was not associated with age, baseline BNP, BUN, eGFR, diuretic dose administered, gender, ethnicity, ischemic etiology, hypertension, diabetes mellitus, or medication use ( $p>0.10$ for all). Proportion of patients with impaired 
natriuretic response were similar between those with preserved versus impaired left ventricular ejection fraction. Meanwhile, baseline hyponatremia (defined as serum sodium $<135 \mathrm{mg} / \mathrm{dL}, \mathrm{n}=18,35 \%$ ), or serum sodium modeled as a continuous variable on day 1 were not associated with diuretic dose, $\mathrm{U}_{\mathrm{Na}}, \mathrm{U}_{\text {Furosemide, }} \mathrm{U}_{\mathrm{Na}}: \mathrm{U}_{\text {Furosemide, }}$ or $\mathrm{FE}_{\mathrm{Na}}($ all $\mathrm{p}>0.05)$.

\section{Natriuretic Response to Continuous Intravenous Furosemide was Associated with Diuresis in ADHF}

We observed that a higher $\mathrm{U}_{\mathrm{Na}}: \mathrm{U}_{\text {Furosemide }}$ ratio corresponded to greater weight loss and net fluid balance after 24 hours from baseline (Spearman's correlation, all $\mathrm{p}<0.001$, Table 2). By logistic regression analysis, higher $\mathrm{U}_{\mathrm{Na}}: \mathrm{U}_{\text {Furosemide }}$ ratio was associated with a 3.6-fold greater likelihood of significant (above median of $>2.1 \mathrm{~L}$ ) net urine output over 24 hours (OR 3.63 [95\% CI $1.47-12.75$ ], $\mathrm{p}=0.003$ ) and a 2.7 -fold greater likelihood of greater (above median of $>0.7 \mathrm{~kg}$ ) weight loss over 24 hours (OR 2.71 [95\%CI $1.16-8.93$ ], $\mathrm{p}=0.018$ ). Furthermore, higher baseline $\mathrm{U}_{\mathrm{Na}}: \mathrm{U}_{\text {Furosemide }}$ ratio correlated with greater 48 -hour and 72hour total net fluid balance and weight loss from baseline as well ( $\mathrm{p}<0.05$ for all, data not shown). Figure 1 illustrates that both diminished weight loss and net fluid balance over 24 hours of continuous intravenous furosemide were observed when $\mathrm{U}_{\mathrm{Na}}: \mathrm{U}_{\text {Furosemide }}$ ratios were $<2 \mathrm{mmol} / \mathrm{mg}$. Of those who did not have baseline hyponatremia $(\mathrm{n}=34)$ and who went onto develop hyponatremia with IV diuresis ( $\mathrm{n}=14$ of $34,41 \%$ ) versus those who did not, there were no differences in diuretic dose, $\mathrm{U}_{\mathrm{Na}}, \mathrm{U}_{\text {Furosemide, }} \mathrm{U}_{\mathrm{Na}}: \mathrm{U}_{\text {Furosemide, }} \mathrm{FE}_{\mathrm{Na}}$ (all $\mathrm{p}>0.05$ ). Neither baseline nor follow-up hyponatremia was associated with differences in net fluid output or weight loss when compared to those without hyponatremia.

\section{Insufficient Natriuretic Response to Continuous Intravenous Furosemide was Associated with WRF and Adverse Outcomes in ADHF}

In this study cohort, 13 patients (25\%) developed WRF within 5 days of admission. Patients who developed WRF had significantly lower levels of $\mathrm{U}_{\mathrm{Na}}: \mathrm{U}_{\text {Furosemide }}$ ratio when compared to those without WRF (mean 2.03 [IQR 0.85 - 3.39] versus 3.09 [1.69 - 8.38] mmol/mg, $\mathrm{p}=0.044$ ). Logistic regression analysis demonstrates that lower $\mathrm{U}_{\mathrm{Na}}: \mathrm{U}_{\text {Furosemide }}$ ratio was associated with greater likelihood of developing subsequent WRF (unadjusted OR $=2.47$ [95\% CI $1.08-7.04$ ], $\mathrm{p}=0.03$ ), and this correlation even strengthened after adjustment with age and baseline eGFR (adjusted OR 3.01; 95\%CI $1.15-10.22, \mathrm{p}=0.021$ ) or with age and baseline creatinine (adjusted OR 3.22; 95\% CI $1.21-11.81, \mathrm{p}=0.016$ ).

Over a mean follow-up duration of 5 months, there were 37 individuals experiencing any of the following adverse clinical events (71\%, several have experienced more than one event): death (23 patients, 44\%), cardiac transplantation (8 patients, 15\%); and/or heart failure rehospitalization (23 patients, 44\%). Figure 1 illustrates that poor long-term prognosis was associated with $\mathrm{U}_{\mathrm{Na}}: \mathrm{U}_{\text {Furosemide }}$ ratio $<2 \mathrm{mmol} / \mathrm{mg}$, regardless of eGFR. In Cox proportional hazards analysis, lower $\mathrm{U}_{\mathrm{Na}}: \mathrm{U}_{\text {Furosemide }}$ ratio was associated with increased risk of death, cardiac transplantation, or heart failure re-hospitalization, even when adjusted for eGFR (Table 3). In multivariate analysis, lower $\mathrm{U}_{\mathrm{Na}}: \mathrm{U}_{\text {Furosemide }}$ ratio was associated with greater likelihood of adverse long-term clinical outcomes after individually adjustment for age, admission $\mathrm{S}_{\mathrm{Cr}}$, left ventricular ejection fraction, BNP, diabetes mellitus, hypertension, or chronic kidney disease (all $\mathrm{p}<0.05$, data not shown). Specifically, $\mathrm{U}_{\mathrm{Na}}: \mathrm{U}_{\text {Furosemide }}$ ratio $<2$ 
$\mathrm{mmol} / \mathrm{mg}$ was associated with adverse clinical events after adjusted for age and eGFR (hazard ratio [HR] 2.22, 95\% confidence interval 1.08-4.49, p<0.032). Lower $\mathrm{U}_{\mathrm{Na}}: \mathrm{U}_{\text {Furosemide }}$ ratio was still associated with greater likelihood of adverse long-term clinical outcomes after individual adjustment for common risk factors such as high serum BUN or low serum sodium. In contrast, there was no association between loop diuretic total dose $(\mathrm{p}=0.42)$ or infusion rate $(\mathrm{p}=0.28)$ and long-term outcomes.

\section{Urine Sodium Excretion and Long-term Clinical Outcomes in ADHF}

We also explored the potential clinical utility of measuring spot urine electrolytes during continuous intravenous loop diuretic as potential bedside surrogate in determining the effectiveness of decongestion strategies. Mean and median baseline $\mathrm{U}_{\mathrm{Na}}$ were $69 \pm 35 \mathrm{mM}$ and 70 [IQR 42-96] mM. Patients who developed WRF also had significantly lower $\mathrm{U}_{\mathrm{Na}}$ (45 [IQR 21 - 72] versus 82 [IQR 49 - 97] mM, p=0.016). Similar to $\mathrm{U}_{\mathrm{Na}}: \mathrm{U}_{\text {Furosemide, we }}$ observed direct correlations between $\mathrm{U}_{\mathrm{Na}}$ and $\mathrm{FE}_{\mathrm{Na}}$ with 24-hour urine output, 24-hour net fluid output, and 24-hour weight loss (all p<0.001, Table 2 and Figure 2). In logistic regression analysis, higher $\mathrm{U}_{\mathrm{Na}}$ was associated with greater ( $\geq$ median or 2.1L) 24-hour net fluid output (unadjusted OR 7.96 [95\%CI 2.20-50.65], p<0.001) and greater ( $\geq$ median or $0.7 \mathrm{~kg}$ ) 24-hour net weight loss (unadjusted OR 4.38 [95\%CI 1.48-20.39], p=0.005). Nevertheless, both $\mathrm{U}_{\mathrm{Na}}$ and $\mathrm{FE}_{\mathrm{Na}}$ was associated with more insufficient diuresis (24-hour net urine output $<1 \mathrm{~L}$ ) with comparable accuracy than $\mathrm{U}_{\mathrm{Na}}: \mathrm{U}_{\text {Furosemide }}$ by AUC analysis. However, $\mathrm{FE}_{\mathrm{Na}}$ (unadjusted HR 1.05 [95\% CI 0.52-2.04], p=0.886) has weaker association with the likelihood of insufficient diuresis than that of $\mathrm{U}_{\mathrm{Na}}$ (unadjusted HR 2.05 [95\% CI 1.04-3.96], $\mathrm{p}=0.038$; adjusted HR 2.06 [95\%CI 1.03-4.04, $\mathrm{p}=0.041$ ).

\section{DISCUSSION}

Despite multiple attempted made by several clinical trials aiming to clarify the optimal use of loop diuretics in the management of congestion, ${ }^{9-11}$ the appropriate selection of dose, route, and determination of effectiveness of loop diuretic therapy in ADHF remain largely empirical. There are several novel findings from this single-center, prospective mechanistic study. First and foremost, we demonstrated the association between impaired natriuretic response to continuous furosemide infusion (estimated by amount of urine sodium excretion per unit urinary furosemide) and the greater likelihood of future adverse long-term outcomes, which was independent and incremental to traditional measures of intrinsic glomerular filtration. Second, we confirmed the concordance between degree of urine sodium excretion using a spot collection sample and the ability to produce diuresis and weight loss with steady-state continuous furosemide infusion in the setting of ADHF. In particular, we demonstrated that insufficient urine sodium excretion on spot measurement (absolute $\mathrm{U}_{\mathrm{Na}}<50 \mathrm{mmol}$ ) was associated with relatively diminished net urine output and weight loss independent of measures of glomerular filtration. Interestingly, the absolute amount of spot urine sodium excretion during continuous intravenous infusion is far more predictive than fractional excretion of sodium, likely due to confounding effects of impaired urine sodium excretion due to underlying impairment of glomerular filtration. Taken together, these findings imply potential distinct mechanisms of insufficient sodium excretion 
during diuretic administration that can affect adequate decongestion during ADHF beyond underlying impaired glomerular filtration.

At the tubular level, loop diuretic drugs act by inhibiting the luminal $\mathrm{Na}^{+}, \mathrm{K}^{+}, 2 \mathrm{Cl}^{-}$ cotransporter (NKCC2) in the thick ascending limb of the loop of Henle, preventing the transport of sodium from the tubular lumen of the loop of Henle into the basolateral interstitium. As a result, the tubular lumen becomes more hypertonic and the interstitium less so, diminishing the osmotic gradient required for water reabsorption. Successful diuresis therefore hinges upon effective delivery of loop diuretics to inhibit NKCC2 (pharmacokinetics) and their ability to produce natriuretic gradient (pharmacodynamics). Assessment of the amount of urine sodium excreted per given furosemide delivered may therefore reflect the true "function" of the kidneys during ADHF therapy - to relieve congestion in response to loop diuretics. Our findings that higher $\mathrm{U}_{\mathrm{Na}}$ and $\mathrm{U}_{\mathrm{Na}}: \mathrm{U}_{\text {Furosemide }}$ tracked with greater diuresis and effective weight loss are therefore consistent with the notion that effective delivery of furosemide as well as the availability of "substrate" (i.e. sodium) at the tubular level both play important roles in effective decongestive therapy ${ }^{12}$.

The incremental predictive value of natriuretic determinants in adverse clinical endpoints even after adjusting for traditional indices of renal function is relatively unexpected and deserves some discussion. Traditionally, BUN and creatinine are standard renal indices that represent the overall ability of the kidneys to effectively filter or secrete unwanted substances in the form of urine excretion. In our cohort, we observed a relative dissociation between urine sodium excretion and these traditional measures of renal indices. Thus, quantifying natriuretic responses to furosemide may provide a different dimension in a pertubated condition whereby the amount of urine sodium excreted in response to pharmacological inhibition of $\mathrm{NKCC} 2$ is being measured. It is therefore conceivable that urinary sodium excretion during continuous loop diuretic therapy may represent a more physiologic (functional) assessment of decongestive reserve by the kidneys than a static metric of renal function. To further support this concept, we observed that $\mathrm{FE}_{\mathrm{Na}}$ (i.e. when accounts for urine creatinine secretion) was less predictive of adverse clinical outcomes in ADHF than $\mathrm{U}_{\mathrm{Na}}$ itself in our study. Indeed, these associative findings do not indicate causality, yet these findings imply that disease severity can be illustrated at the level of urine sodium excretion and their relationship with furosemide delivery at the tubules. In other words, the inability to mount an appropriate diuretic response to relieve congestion heralds someone in more advanced stage of their disease. This aspect is currently not well appreciated in outcomes research in ADHF.

Our findings are concordant with prior reports showing relatively low sodium excretion itself despite diuretic therapy in refractory patients with heart failure. ${ }^{13,14}$ Indeed, the relatively strong correlations between $\mathrm{U}_{\mathrm{Na}}$ and diuretic effectiveness in the setting of loop diuretic use may be clinically insightful in providing guidance to quantify the effectiveness of decongestion therapy ${ }^{15}$. There are important diagnostic and therapeutic implications with this distinction, as our clinical understanding of renal impairment (either as confounding comorbidity or as an adverse therapeutic consequence) and determination of therapeutic success/failure rely heavily on tracking changes in BUN or creatinine rather than the ability for the kidneys to relieve sodium. As treatment modalities targeting patients with WRF via 
BUN/creatinine measurements may not reflect cardio-renal disease progression ${ }^{16,17}$, further studies are therefore warranted to determine if natriuretic responses are more appropriate surrogates for effective treatment strategies in ADHF than traditional renal indices.

The cause(s) of WRF during the ADHF treatment can be multifactorial, ${ }^{18}$ and may occur as a combination of impaired renal perfusion, insufficient drug delivery, ineffective tubular drug responses, or in relatively rare instances direct tubular injury and damage. Systemic perfusion remains an important determinant or adequate renal function in the setting of ADHF $,{ }^{19},{ }^{20}$ and the degree of tubular injury maybe less than other forms of acute kidney injury despite rising serum creatinine. ${ }^{21,22}$ On the other hand, over-activation of the SNS and RAAS can lead to hemodynamic perturbations and worsening congestion, leading to further neurohormonal activation. Both RAAS and SNS are early stimulators of $\mathrm{U}_{\mathrm{Na}}$ absorption, whether or not there is underlying intrinsic renal impairment. This may be due to the fact that direct neurohumoral activation secondary to loop diuretic treatment at the NKCC2 symporter is essential to achieve chloride concentrations in macula densa cells that are able to inhibit renin secretion. Our observations regarding a lower $\mathrm{U}_{\mathrm{Na}}$ may therefore represent the integrate product of increased SNS and RAAS activation in the setting of ADHF.

Our results have some implications to the approach of appropriate diuretic dosing in ADHF, which is currently reactive rather than proactive. Dosing decongestive therapy with loop diuretics remains largely empirical. Historically, healthcare providers have gauged the degree of severity of intrinsic renal impairment, combined with the home diuretic requirements to come up with an intravenous equivalent (or increment) of diuretic dose to be administered, which often leads to ineffective decongestion prior to discharge. Reliance on determining post-treatment urine output and weight loss to evaluate adequate dosing of diuretic regimen (often at least a day or two after initial dosing) may lead to unavoidable delays in dose adjustments. Urine electrolyte measurements have been widely available at the bedside, but clinicians have always been taught to preclude testing urine electrolytes (particularly $\mathrm{U}_{\mathrm{Na}}$ ) in the setting of ADHF due to inaccuracies as a result of various confounders such as diuretic pharmacokinetics and pharmacodynamics, volume status, sodium balance, and intrinsic renal dysfunction. Further studies are warranted to determine if $\mathrm{U}_{\mathrm{Na}}$ may provide clinical insights for loop diuretic titration (and whether such strategies can be extended to assess adequacy in bolus or even oral administrations).

\section{Study Limitations}

There are several limitations in this prospective cohort study. First, this was a single advanced tertiary center study and so suffers from referral bias of patients who are in more advanced stage of their disease with a high post-admission event rate (which is consistent with the use of continuous furosemide infusion). These findings may therefore not be reproducible patients in milder stages of heart failure. Secondly, we assumed a period of at least 3 hours required for plasma and hence urinary levels of furosemide to equilibrate upon starting the infusion. However due the need to intervene in patients by performing an additional blood draw hence changing the observational nature of this study design, the study did not objectively confirm equilibration of furosemide levels by urine and plasma 
measurement of levels after starting the infusion. In reality however, most patients had urine sample taken $>3$ hours (but $<24$ hours) after initiation of therapy and had a bolus of furosemide at time of starting the infusion to "kickstart" their diuresis. Also, the exact time between admission to enrollment was not recorded. We should also caution that our findings only apply to a patient population early in their treatment course that has received continuous furosemide infusion beyond its expected half-life (where therapeutic furosemide levels are assumed to have reached steady state). ${ }^{5,23}$ Thirdly, we did not control for other factors that influence urinary electrolytes and urine output, including dietary sodium, glucose, effect of posture, dietary influence, and blood pressure. Also, clinical response as defined by urine output and weight loss was reliant on clinical nursing protocols and measurements and not in a strictly controlled clinical trial environment. Such studies logistically would require a clinical research unit/laboratory with dedicated research nurses and ancillary staff. However, since our study was performed in a clinical setting, they do represent "real world" patients and presentations, broadening the applicability of its findings.

\section{CONCLUSIONS}

In patients with ADHF receiving continuous furosemide infusion, impaired natriuretic response to furosemide is associated with greater likelihood of WRF and future adverse long-term outcomes that is independent and incremental to intrinsic glomerular filtration.

\section{Acknowledgments}

\section{FUNDING}

This research was supported by grant funding from the National Institutes of Health R01HL103931 (W.T.) and K23HL114868 (J.T.), as well as the Cleveland Clinic Clinical Research Unit of the Case Western Reserve University CTSA (UL1TR 000439).

\section{REFERENCES}

1. Yancy CW, Jessup M, Bozkurt B, Butler J, Casey DE Jr, Drazner MH, et al. ACCF/AHA Guideline for the Management of Heart Failure: Executive Summary: A Report of the American College of Cardiology Foundation/American Heart Association Task Force on Practice Guidelines. Circulation. 2013; 128:1810-1852. 2013. [PubMed: 23741057]

2. Brater DC. Resistance to loop diuretics. Why it happens and what to do about it. Drugs. 1985; 30:427-443. [PubMed: 3905337]

3. Ellison DH. Diuretic therapy and resistance in congestive heart failure. Cardiology. 2001; 96:132143. [PubMed: 11805380]

4. Vargo DL, Kramer WG, Black PK, Smith WB, Serpas T, Brater DC. Bioavailability, pharmacokinetics, and pharmacodynamics of torsemide and furosemide in patients with congestive heart failure. Clin Pharmacol Ther. 1995; 57:601-609. [PubMed: 7781259]

5. Brater DC, Chennavasin P, Seiwell R. Furosemide in patients with heart failure: shift in doseresponse curves. Clin Pharmacol Ther. 1980; 28:182-186. [PubMed: 7398185]

6. Wilcox CS, Mitch WE, Kelly RA, Skorecki K, Meyer TW, Friedman PA, et al. Response of the kidney to furosemide. I. Effects of salt intake and renal compensation. J Lab Clin Med. 1983; 102:450-458. [PubMed: 6886524]

7. Kaissling B, Bachmann S, Kriz W. Structural adaptation of the distal convoluted tubule to prolonged furosemide treatment. Am J Physiol. 1985; 248:F374-F381. [PubMed: 3976898] 
8. Iyengar S, Abraham WT. Diuretic resistance in heart failure. Curr Heart Fail Rep. 2006; 3:41-45. [PubMed: 16684496]

9. Bart BA, Goldsmith SR, Lee KL, Givertz MM, O'Connor CM, Bull DA, et al. Ultrafiltration in decompensated heart failure with cardiorenal syndrome. N Engl J Med. 2012; 367:2296-2304. [PubMed: 23131078]

10. Felker GM, Lee KL, Bull DA, Redfield MM, Stevenson LW, Goldsmith SR, et al. Diuretic strategies in patients with acute decompensated heart failure. N Engl J Med. 2011; 364:797-805. [PubMed: 21366472]

11. Konstam MA, Gheorghiade M, Burnett JC Jr, Grinfeld L, Maggioni AP, Swedberg K, et al. Effects of oral tolvaptan in patients hospitalized for worsening heart failure: the EVEREST Outcome Trial. JAMA. 2007; 297:1319-1331. [PubMed: 17384437]

12. Verbrugge FH, Dupont M, Steels P, Grieten L, Swennen Q, Tang WH, et al. The kidney in congestive heart failure: 'are natriuresis, sodium, and diuretics really the good, the bad and the ugly?'. Eur J Heart Fail. 2014; 16:133-142. [PubMed: 24464967]

13. Alattar FT, Imran N, Debari VA, Mallah KN, Shamoon FE. Fractional excretion of sodium predicts worsening renal function in acute decompensated heart failure. Exp Clin Cardiol. 2010; 15:e65-e69. [PubMed: 20959883]

14. Ali SS, Olinger CC, Sobotka PA, Dahle TG, Bunte MC, Blake D, et al. Loop diuretics can cause clinical natriuretic failure: a prescription for volume expansion. Congest Heart Fail. 2009; 15:1-4. [PubMed: 19187399]

15. Testani JM, Brisco MA, Turner JM, Spatz ES, Bellumkonda L, Parikh CR, et al. Loop Diuretic Efficiency: A Metric of Diuretic Responsiveness with Prognostic Importance in Acute Decompensated Heart Failure. Circ Heart Fail. Dec 30.2013 2013; Published online.

16. Testani JM, Cappola TP, McCauley BD, Chen J, Shen J, Shannon RP, et al. Impact of worsening renal function during the treatment of decompensated heart failure on changes in renal function during subsequent hospitalization. Am Heart J. 2011; 161:944-949. [PubMed: 21570527]

17. Testani JM, McCauley BD, Chen J, Shumski M, Shannon RP. Worsening renal function defined as an absolute increase in serum creatinine is a biased metric for the study of cardio-renal interactions. Cardiology. 2010; 116:206-212. [PubMed: 20689277]

18. Verbrugge FH, Dupont M, Steels P, Grieten L, Malbrain M, Tang WH, et al. Abdominal contributions to cardiorenal dysfunction in congestive heart failure. J Am Coll Cardiol. 2013; 62:485-495. [PubMed: 23747781]

19. Dupont M, Mullens W, Finucan M, Taylor DO, Starling RC, Tang WH. Determinants of dynamic changes in serum creatinine in acute decompensated heart failure: the importance of blood pressure reduction during treatment. Eur J Heart Fail. 2013; 15:433-440. [PubMed: 23288912]

20. Testani JM, Coca SG, McCauley BD, Shannon RP, Kimmel SE. Impact of changes in blood pressure during the treatment of acute decompensated heart failure on renal and clinical outcomes. Eur J Heart Fail. 2011; 13:877-884. [PubMed: 21693504]

21. Dupont M, Shrestha K, Singh D, Awad A, Kovach C, Scarcipino M, et al. Lack of significant renal tubular injury despite acute kidney injury in acute decompensated heart failure. Eur J Heart Fail. 2012; 14:597-604. [PubMed: 22505396]

22. Verbrugge FH, Dupont M, Shao Z, Shrestha K, Singh D, Finucan M, et al. Novel urinary biomarkers in detecting acute kidney injury, persistent renal impairment, and all-cause mortality following decongestive therapy in acute decompensated heart failure. J Card Fail. 2013; 19:621628. [PubMed: 24054338]

23. Brater DC. Update in diuretic therapy: clinical pharmacology. Semin Nephrol. 2011; 31:483-494. [PubMed: 22099505] 

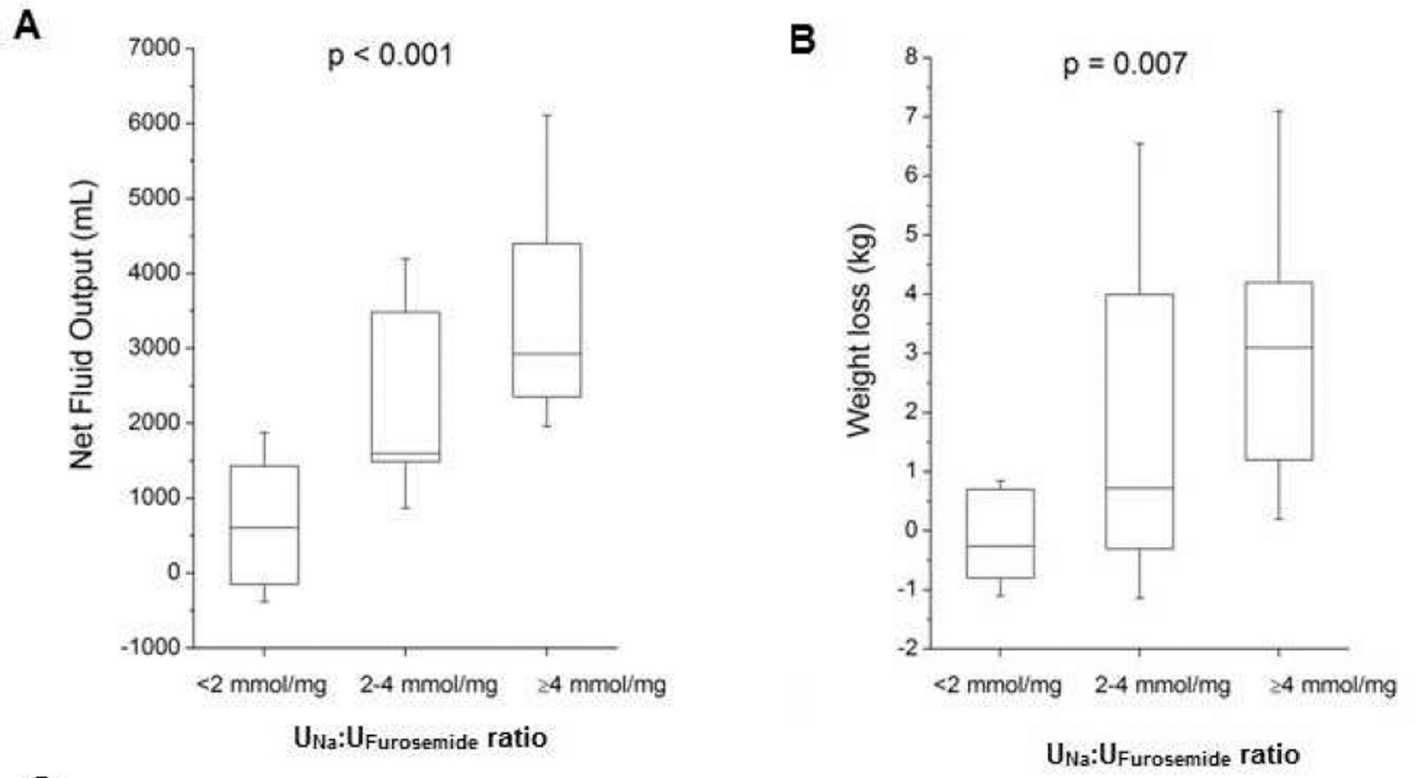

C

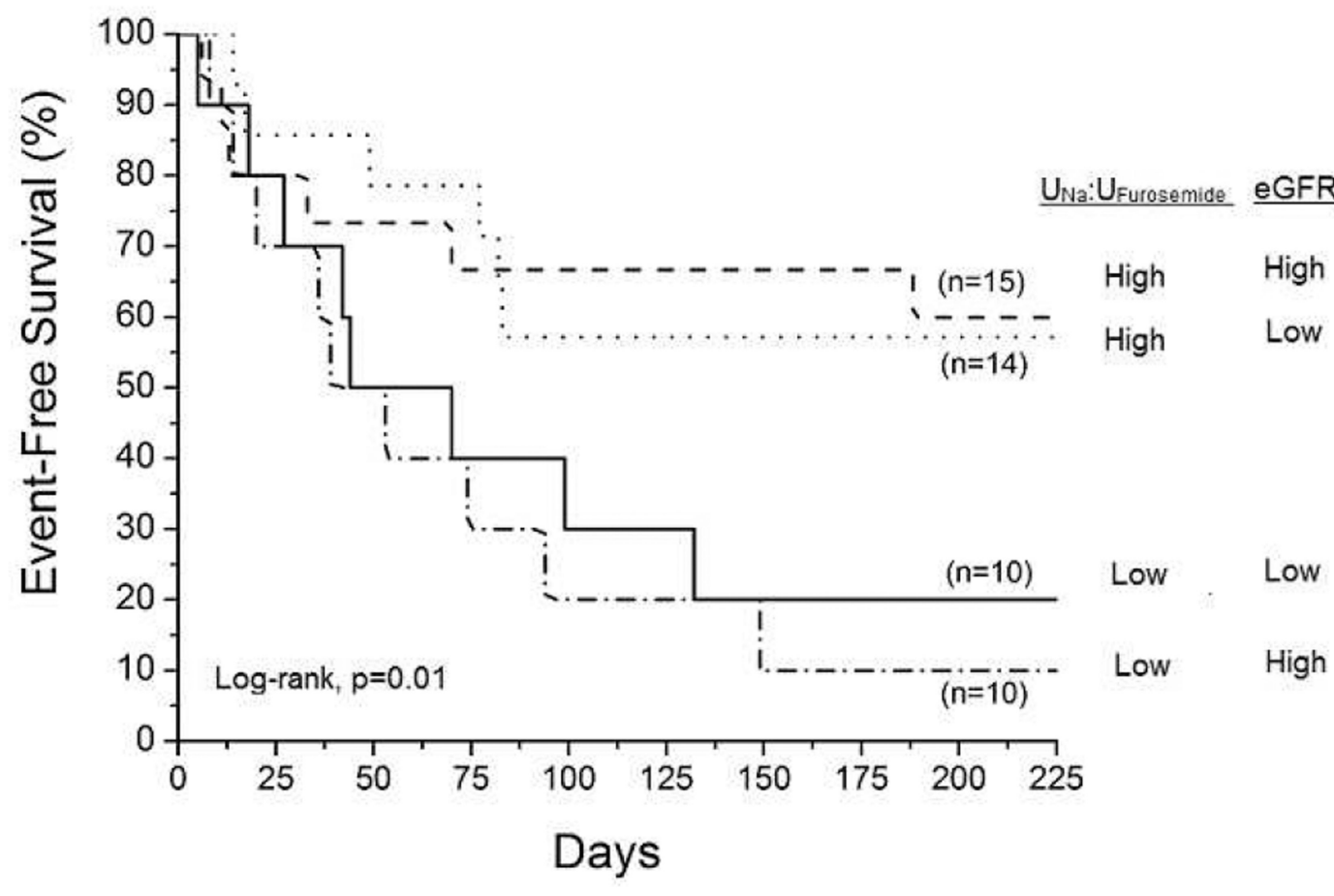

Figure 1. Diuretic Response to Continuous Intravenous Furosemide and Clinical Outcomes According to $\mathrm{U}_{\mathrm{Na}}$ : $\mathbf{U}_{\text {Furosemide Ratio }}$

Caption: Panel A: Comparison across tertiles of $\mathrm{U}_{\mathrm{Na}}$ : $\mathrm{U}_{\text {Furosemide }}$ ratio on net fluid output; Panel B: Comparison across tertiles of $\mathrm{U}_{\mathrm{Na}}$ : $\mathrm{U}_{\text {Furosemide }}$ ratio on net weight loss; Panel C: Kaplan-Meier Analysis of adverse clinical outcomes (all-cause mortality, cardiac transplantation or heart failure re-hospitalization) in patients with acute decompensated heart failure receiving continuous intravenous furosemide $(n=52)$ stratified according to optimal $\mathrm{U}_{\mathrm{Na}}: \mathrm{U}_{\text {Furosemide }}$ cut-off $(2.27 \mathrm{mmol} / \mathrm{mg})$ and median estimated glomerular filtration rate (eGFR $50 \mathrm{ml} / \mathrm{min} / 1.73 \mathrm{~m}^{2}$ ). 
A

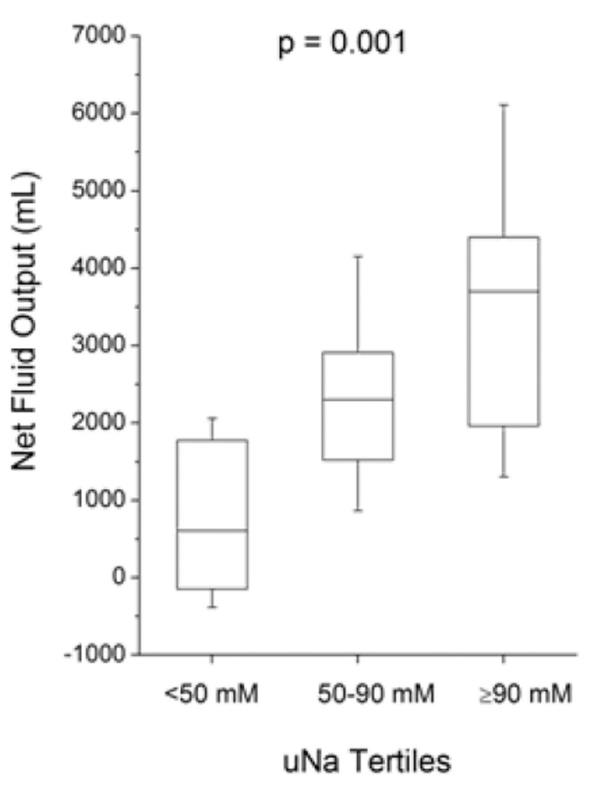

C

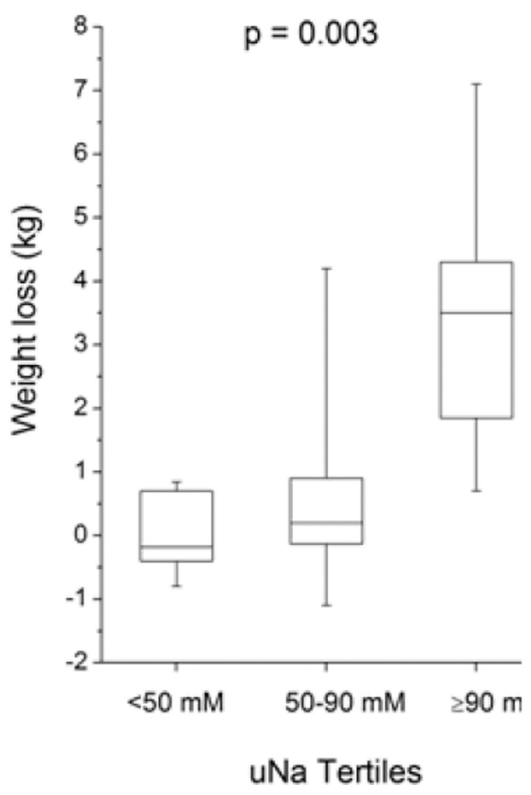

B

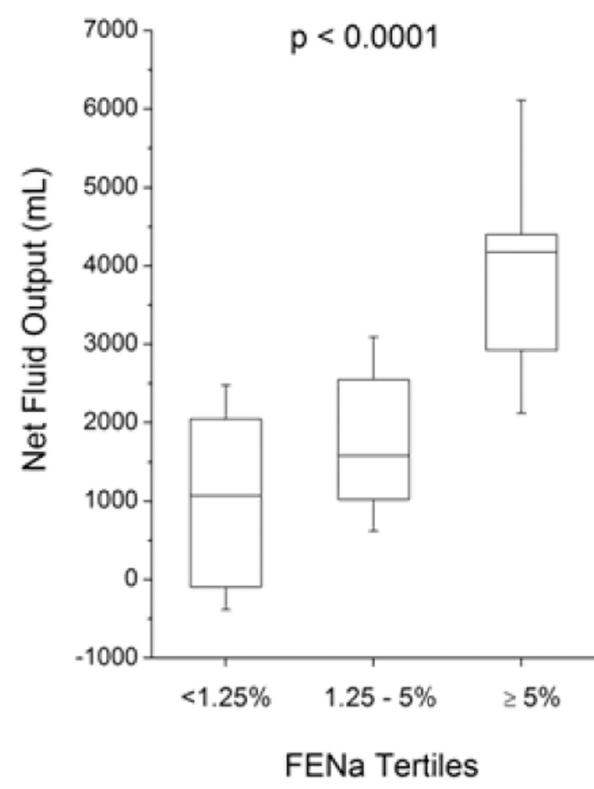

D

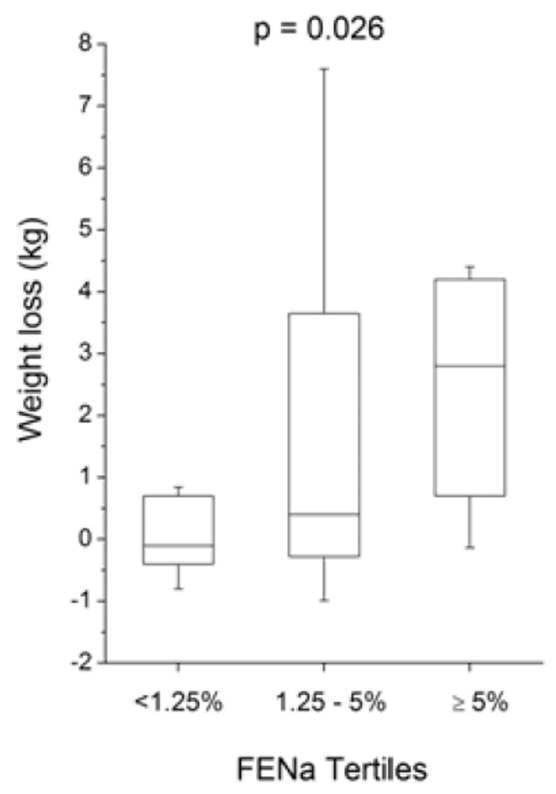

Figure 2. Diuretic Response to Continuous Intravenous Furosemide According to Urine Sodium Excretion ( $\left.\mathbf{U}_{\mathbf{N a}}\right)$ and Fractional Excretion of Urine Sodium $\left(\mathbf{F E}_{\mathbf{N a}}\right)$

Caption: Panel A: Comparison across tertiles of $\mathrm{U}_{\mathrm{Na}}$ on net fluid output; Panel B:

Comparison across tertiles of $\mathrm{FE}_{\mathrm{Na}}$ on net fluid output; Panel $\mathrm{C}$ : Comparison across tertiles of $\mathrm{U}_{\mathrm{Na}}$ on net weight loss; Panel D: Comparison across tertiles of $\mathrm{FE}_{\mathrm{Na}}$ on net weight loss 


\section{Table 1}

Baseline Characteristics in Acute Decompensated Heart Failure Patients Receiving Continuous Intravenous Furosemide according to median estimated Glomerular Filtration Rate (eGFR at $50 \mathrm{ml} / \mathrm{min} / 1.73 \mathrm{~m}^{2}$ )

\begin{tabular}{|c|c|c|c|c|}
\hline Demographics & $\begin{array}{l}\text { Overall study } \\
\text { cohort } \\
(n=52)\end{array}$ & $\begin{array}{c}\text { eGFR }<50 \\
\mathrm{ml} / \min / 1.73 \mathrm{~m}^{2} \\
(\mathrm{n}=26)\end{array}$ & $\begin{array}{c}\text { eGFR } \geq 50 \\
\mathrm{ml} / \mathrm{min} / 1.73 \mathrm{~m}^{2} \\
(\mathrm{n}=26)\end{array}$ & p-value \\
\hline Age (years) & $61 \pm 15$ & $64 \pm 13$ & $57 \pm 15$ & 0.105 \\
\hline Men, n (\%) & $35(67 \%)$ & $16(62 \%)$ & $19(73 \%)$ & 0.374 \\
\hline African American, n (\%) & $16(31 \%)$ & $7(27 \%)$ & $9(35 \%)$ & 0.548 \\
\hline \multicolumn{5}{|l|}{ Medical History } \\
\hline Ischemic heart failure, n (\%) & $23(46 \%)$ & $10(40 \%)$ & $13(52 \%)$ & 0.394 \\
\hline LV ejection fraction (\%) & $28 \pm 15$ & $30 \pm 15$ & $25 \pm 15$ & 0.290 \\
\hline Diabetes Mellitus, n (\%) & $21(40 \%)$ & $14(54 \%)$ & $7(27 \%)$ & 0.046 \\
\hline Hypertension, n (\%) & $31(60 \%)$ & $17(65 \%)$ & $14(54 \%)$ & 0.396 \\
\hline Hyperlipidemia, n (\%) & $21(40 \%)$ & $13(50 \%)$ & $8(31 \%)$ & 0.156 \\
\hline Coronary Artery Disease, n (\%) & $23(44 \%)$ & $11(42 \%)$ & $12(46 \%)$ & 0.780 \\
\hline Atrial Fibrillation, n (\%) & $19(37 \%)$ & $11(42 \%)$ & $8(31 \%)$ & 0.387 \\
\hline COPD, n (\%) & $8(15 \%)$ & $5(19 \%)$ & $3(12 \%)$ & 0.440 \\
\hline \multicolumn{5}{|l|}{ Baseline Medications } \\
\hline $\begin{array}{l}\text { ACE Inhibitors and/or ARBs, } \mathrm{n} \\
(\%)\end{array}$ & $26(51 \%)$ & $9(36 \%)$ & $17(65 \%)$ & 0.035 \\
\hline Beta blockers, n (\%) & $35(67 \%)$ & $18(72 \%)$ & $17(65 \%)$ & 0.610 \\
\hline Loop diuretics, n (\%) & $47(92 \%)$ & $23(92 \%)$ & $24(92 \%)$ & 0.967 \\
\hline Aldosterone antagonists, n (\%) & $18(35 \%)$ & $8(32 \%)$ & $10(38 \%)$ & 0.629 \\
\hline Digoxin, n (\%) & $14(27 \%)$ & $5(20 \%)$ & $9(35 \%)$ & 0.240 \\
\hline \multicolumn{5}{|l|}{ Blood laboratory findings } \\
\hline Serum sodium $(\mathrm{mM})$ & $135 \pm 5$ & $135 \pm 6$ & $136 \pm 3$ & 0.713 \\
\hline Serum BUN (mg/dL) & $42 \pm 21$ & $57 \pm 19$ & $27 \pm 11$ & $<0.0001$ \\
\hline Serum Creatinine (mg/dL) & $1.8 \pm 0.9$ & $2.4 \pm 0.8$ & $1.1 \pm 0.3$ & $<0.0001$ \\
\hline eGFR $\left(\mathrm{mL} / \mathrm{min} / 1.73 \mathrm{~m}^{2}\right)$ & $55 \pm 31$ & $30 \pm 10$ & $80 \pm 24$ & $<0.0001$ \\
\hline BNP, $\mathrm{pg} / \mathrm{mL}$ & $\begin{array}{c}758 \\
(423-2187)\end{array}$ & $\begin{array}{c}1,476 \\
(467-2,474)\end{array}$ & $\begin{array}{c}879 \\
(450-2,021) \\
\end{array}$ & 0.464 \\
\hline Furosemide, continuous (mg/hr) & $13 \pm 6$ & $14 \pm 6$ & $11 \pm 6$ & 0.071 \\
\hline \multicolumn{5}{|l|}{ Spot Urine Measurements } \\
\hline $\mathrm{U}_{\mathrm{Na}}(\mathrm{mmol})$ & $\begin{array}{c}70 \\
(42-96)\end{array}$ & $\begin{array}{c}70 \\
(51-94)\end{array}$ & $\begin{array}{c}74 \\
(27-99)\end{array}$ & 0.564 \\
\hline $\mathrm{U}_{\mathrm{Na}} / \mathrm{U}_{\mathrm{Cr}}(\mathrm{mmol} / \mathrm{mg})$ & $\begin{array}{c}0.20 \\
(0.07-0.44)\end{array}$ & $\begin{array}{c}0.21 \\
(0.10-0.48)\end{array}$ & $\begin{array}{c}0.20 \\
(0.04-0.42)\end{array}$ & 0.493 \\
\hline $\mathrm{U}_{\text {Furosemide }}(\mathrm{mg} / \mathrm{L})$ & $24(13-37)$ & $28(14-36)$ & $24(11-39)$ & 0.896 \\
\hline $\mathrm{U}_{\text {Furosemide }} / \mathrm{U}_{\mathrm{Cr}}(\mathrm{mg} / \mathrm{mg})$ & $6(4-11)$ & $7(4-13)$ & $5(3-9)$ & 0.294 \\
\hline $\mathrm{U}_{\mathrm{Na}}: \mathrm{U}_{\text {Furosemide }}$ ratio & $\begin{array}{c}2.86 \\
(1.40-6.88)\end{array}$ & $\begin{array}{c}2.77 \\
(1.64-6.30)\end{array}$ & $\begin{array}{c}2.86 \\
(0.86-8.17)\end{array}$ & 0.905 \\
\hline
\end{tabular}




\begin{tabular}{|l|c|c|c|c|}
\hline Demographics & $\begin{array}{c}\text { Overall study } \\
\text { cohort } \\
(\mathbf{n = 5 2})\end{array}$ & $\begin{array}{c}\text { eGFR }<\mathbf{5 0} \\
\mathbf{m l} / \mathbf{m i n} / \mathbf{1 . 7 3 m ^ { 2 }} \\
(\mathbf{n = 2 6})\end{array}$ & $\begin{array}{c}\text { eGFR } \mathbf{5 0} \\
\mathbf{m l} \mathbf{m i n} / \mathbf{1 . 7 3 \mathbf { m } ^ { 2 }} \\
(\mathbf{n = 2 6})\end{array}$ & p-value \\
\hline $\mathrm{FE}_{\mathrm{Na}}(\%)$ & $\begin{array}{c}2.50 \\
(0.81-5.94)\end{array}$ & $\begin{array}{c}4.86 \\
(1.37-9.43)\end{array}$ & $\begin{array}{c}1.41 \\
(0.33-3.89)\end{array}$ & 0.004 \\
\hline Treatment outcomes & & & & \\
\hline 24 hour urine output $(\mathrm{mL})$ & $3,672 \pm 2,021$ & $3,860 \pm 1,964$ & $3,421 \pm 2,125$ & 0.381 \\
\hline 24 hour output minus input $(\mathrm{mL})$ & $2,256 \pm 2,062$ & $2,668 \pm 1,628$ & $1,736 \pm 2,454$ & 0.072 \\
\hline 24 hour weight loss $(\mathrm{kg})$ & $1.53 \pm 2.60$ & $1.4 \pm 2.4$ & $1.7 \pm 3.0$ & 0.961 \\
\hline Worsening renal function, $\mathrm{n}(\%)$ & $13(25 \%)$ & $18(69 \%)$ & $21(81 \%)$ & 0.335 \\
\hline
\end{tabular}

Abbreviations: LV, left ventricular; DM, diabetes mellitus; HTN, hypertension, CKD, chronic kidney disease; HPL, hyperlipidemia; CAD, coronary artery disease; $\mathrm{COPD}$, chronic obstructive pulmonary disease; ACE, angiotensin-converting enzyme; ARB, angiotensin receptor blocker; BUN, blood urea nitrogen; eGFR, estimated glomerular filtration rate; BNP, B-type natriuretic peptide; UNa, urine sodium; UFurosemide, urine furosemide; $\mathrm{U}_{\mathrm{Cr}}$, urine creatinine; $\mathrm{FENa}_{\mathrm{Na}}$, fractional excretion of sodium. 


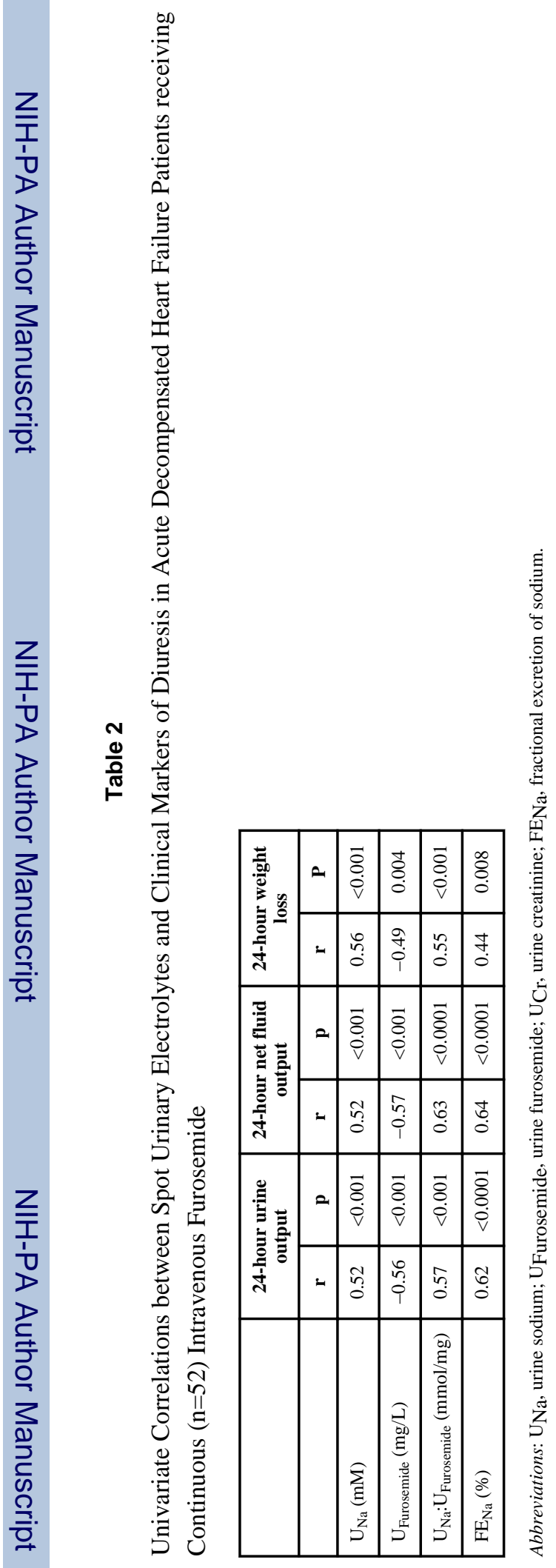

J Card Fail. Author manuscript; available in PMC 2015 June 01. 


\section{Table 3}

Unadjusted and adjusted odds ratios and hazard ratios for worsening renal function and adverse cardiac events for different measurements of urine sodium excretion in acute decompensated heart failure.

\begin{tabular}{|llclc|}
\hline & $\begin{array}{l}\text { Worsening Renal } \\
\text { Function } \\
\text { (Odds ratio [95\% CI] })\end{array}$ & $\begin{array}{c}\text { P } \\
\text { value }\end{array}$ & $\begin{array}{l}\text { Adverse Cardiac } \\
\text { Events } \\
\text { (Hazard ratio [95\% CI] })\end{array}$ & $\begin{array}{c}\text { P } \\
\text { value }\end{array}$ \\
\hline $\mathbf{U}_{\mathbf{N a}}: \mathbf{U}_{\text {Furosemide }}$ & Unadjusted: & & Unadjusted: & \\
& $2.47(1.08-7.04)$ & 0.030 & $1.63(1.10-2.51)$ & 0.013 \\
& Adjusted for age and eGFR: & Adjusted for eGFR: & \\
& $3.01(1.15-10.22)$ & 0.021 & $1.62(1.13-2.39)$ & 0.008 \\
\hline $\mathbf{U}_{\mathbf{N a}}$ & & Unadjusted: & \\
& Unadjusted: & 0.042 & $1.47(1.01-2.08)$ & 0.045 \\
& $2.08(1.03-4.53)$ & & Adjusted for eGFR: & \\
& Adjusted for age and eGFR: & & \\
& $2.52(1.18-6.23)$ & 0.016 & $1.41(1.01-1.96)$ & 0.043 \\
\hline
\end{tabular}

